Check for updates

Cite this: Chem. Sci., 2019, 10, 3836

๑ All publication charges for this article have been paid for by the Royal Society of Chemistry

Received 23rd October 2018

Accepted 21st February 2019

DOI: $10.1039 / \mathrm{c} 8 \mathrm{sc} 04711 \mathrm{a}$

rsc.li/chemical-science

\section{Thermoinduced structural-transformation and thermochromic luminescence in organic manganese chloride crystals $\uparrow$}

\author{
Meng-En Sun, ${ }^{a}$ Yao Li, ${ }^{a}$ Xi-Yan Dong ${ }^{\text {ab }}$ and Shuang-Quan Zang (DD) *a \\ The $\left[\mathrm{Mn}_{2} \mathrm{Cl}_{9}\right]^{5-}$ mode of red emissive $\left(\mathrm{C}_{4} \mathrm{NOH}_{10}\right)_{5} \mathrm{Mn}_{2} \mathrm{Cl}_{9} \cdot \mathrm{C}_{2} \mathrm{H}_{5} \mathrm{OH}$ under thermal treatment will be cleaved \\ into $\left[\mathrm{MnCl}_{4}\right]^{2-}$ in the green emissive $\left(\mathrm{C}_{4} \mathrm{NOH}_{10}\right)_{2} \mathrm{MnCl}_{4}$ with the departure of ethanol. The rapid conversion \\ of luminescence from red to green provides new insight into the luminescence origin and thermal stability \\ of organic-inorganic metal halide hybrids.
}

Metal (Mn, ${ }^{1} \mathrm{Mo},{ }^{2} \mathrm{~W},{ }^{3} \mathrm{~Pb},{ }^{4} \mathrm{Sn},{ }^{5}$ and $\left.\mathrm{Cu}^{6}\right)$ halides (Cl, Br, and I) represent an attractive class of molecular building blocks in luminescent functional materials, which demonstrate potential application in light-emitting diodes, luminescent solar concentrators, photovoltaic modules, etc. ${ }^{7}$ Among them, organic manganese(II) halide hybrids frequently display strong luminescence originating from the $\mathrm{d}-\mathrm{d}$ transition, with lifetimes from microseconds to milliseconds. ${ }^{1,8}$ The reported manganese halides focus on monomanganese species, ${ }^{10,9}$ manganese chain structure ${ }^{1 b, 10}$ and layer structure, ${ }^{11}$ however the oligomeric cluster of manganese(II) remains quite limited, ${ }^{12}$ which deserved careful investigation due to the structural uniqueness.

Crystalline state structure transformation concomitant with a huge change of luminescence involved in chemical bond cleavage or reconstruction upon an external stimulus is very interesting, and is commonly found in framework materials, ${ }^{13}$ yet remains a challenge in cluster compounds. ${ }^{14}$ The emission in manganese(II) halides is sensitive to their ligand-fields. ${ }^{1,8}$ To the best of our knowledge, the combination of stimuliresponsive crystalline structure transformation and luminescence conversion of oligomeric manganese halide clusters has not been reported.

Here, we assembled a binuclear red-emissive manganese chloride cluster crystal $\left(\mathrm{C}_{4} \mathrm{NOH}_{10}\right)_{5} \mathrm{Mn}_{2} \mathrm{Cl}_{9} \cdot \mathrm{C}_{2} \mathrm{H}_{5} \mathrm{OH}$ (1) using morpholine as the organic counter cation. Upon hightemperature induction, $\mathbf{1}$ crystals was fast structurally

${ }^{a}$ College of Chemistry and Molecular Engineering, Zhengzhou University, Zhengzhou 450001, China. E-mail: zangsqzg@zzu.edu.cn

${ }^{b}$ College of Chemistry and Chemical Engineering, Henan Polytechnic University, Jiaozuo 45400o, China

$\dagger$ Electronic supplementary information (ESI) available: Crystallographic details, tables of crystal and refinement data for 1a and 1b; PXRD, TGA UV-vis diffuse reflectance spectra, photoluminescence emission spectra and photoluminescence lifetime spectra of compounds. CCDC 1867428 and 1867436. For ESI and crystallographic data in CIF or other electronic format see DOI: $10.1039 / \mathrm{c} 8 \mathrm{sc} 04711 \mathrm{a}$ transformed into green-emissive $\left(\mathrm{C}_{4} \mathrm{NOH}_{10}\right)_{2} \mathrm{MnCl}_{4}(2)$ crystals in situ. The crystal structural analysis revealed that the manganese dimer in octahedral coordination decomposed into mono manganese species in tetrahedral mode, accompanied by the departure of guest ethanol molecules.

Compound 1 was prepared by mixing manganese chloride $\left(\mathrm{MnCl}_{2}\right)$ and morpholine hydrochloride $\left(\mathrm{C}_{4} \mathrm{NOH}_{10} \mathrm{Cl}\right)(2: 5$ molar ratio) in ethanol at room temperature (R.T.) (Scheme 1). The proportion of $\mathrm{MnCl}_{2}$ and $\mathrm{C}_{4} \mathrm{NOH}_{10} \mathrm{Cl}$ at $1: 2$ and the reaction temperature at $90{ }^{\circ} \mathrm{C}$ were modulated to obtain compound 2. The precise structures of compounds 1 and 2 were determined by single-crystal X-ray diffraction (SCXRD) (Fig. 1a and b, ESI Tables S1-S4†). As depicted in Fig. 1a, the $\mathrm{Mn}^{2+}$ cations occupy the octahedral centre and six chloride ions are located at the vertex. The $\left[\mathrm{Mn}_{2} \mathrm{Cl}_{9}\right]^{5-}$ dimers are faceshared through three coordination chloride ions and embedded periodically in the matrix of organic cations $\mathrm{C}_{4} \mathrm{NOH}_{10}{ }^{+}$. And $\mathrm{C}_{4} \mathrm{NOH}_{10}{ }^{+}$counter ions and ethanol molecules are hydrogen-bonded with $\left[\mathrm{Mn}_{2} \mathrm{Cl}_{9}\right]^{5-}$ dimers in compound $\mathbf{1}$ (ESI Fig. S1†). For compound 2, the $\mathrm{Mn}^{2+}$ cations occupy the tetrahedral centre coordinated by four chloride ions (Fig. 1b). The purity of compounds $\mathbf{1}$ and $\mathbf{2}$ was confirmed by the welloverlapped powder X-ray diffraction (PXRD) patterns between the as-synthesized samples and those simulated from singlecrystal data (ESI Fig. S2 and S3†).

The photophysical properties of compounds $\mathbf{1}$ and $\mathbf{2}$ are fully characterized by UV-vis diffuse reflectance spectra and steady

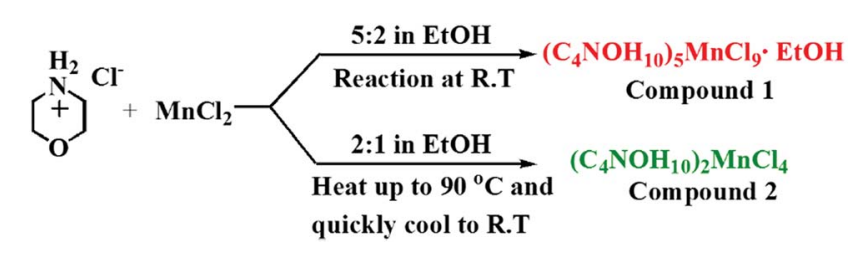

Scheme 1 The synthesis routes to compounds 1 and 2 . 
(a)

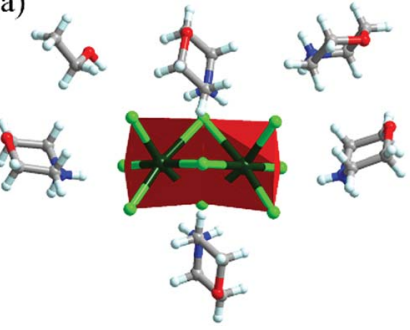

(b)

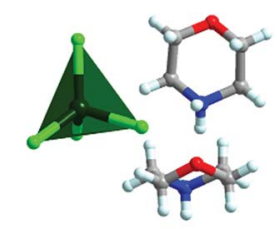

Fig. 1 Crystal structures of compounds 1 (a) and 2 (b). Colour codes: dark green = manganese; bright green = chlorine; red = oxygen; gray $=$ carbon; blue $=$ nitrogen; light turquoise $=$ hydrogen .

state and time resolved photoluminescence (PL) spectra. The peaks around $240-345 \mathrm{~nm}$ for 1 and 2 originate from the transitions within the $\mathrm{C}_{4} \mathrm{NOH}_{10}{ }^{+}$cation, including the $\mathrm{n}-\sigma^{*}$ and $\sigma-$ $\sigma^{*}$ in the UV-vis diffuse reflectance spectra (ESI Fig. S4 $\dagger$ ). And the other peaks around 345-600 $\mathrm{nm}$ for $\mathbf{1}$ and $\mathbf{2}$ can be ascribed to electronic transitions between the ground and the excited states of the $\mathrm{Mn}^{2+}$ ion in the crystal field..$^{15}$ The excitation peak at $520 \mathrm{~nm}$ nearest to the emission peak at $620 \mathrm{~nm}$ corresponds to a characteristic transition from the ground state of the delectron configuration $\left(t_{2 g}\right)^{3}\left(e_{g}\right)^{2}$ to the upper state of the configuration $\left(t_{2 g}\right)^{4}\left(e_{g}\right)^{1}$ (ESI Fig. S5 $\dagger$ ). The excitation peak at $450 \mathrm{~nm}$ nearest to the emission peak at $520 \mathrm{~nm}$ corresponds to a characteristic transition from the ground state of the delectron configuration $\left(\mathrm{e}_{\mathrm{g}}\right)^{2}\left(\mathrm{t}_{2 \mathrm{~g}}\right)^{3}$ to the upper state of the configuration $\left(\mathrm{e}_{\mathrm{g}}\right)^{3}\left(\mathrm{t}_{2 \mathrm{~g}}\right)^{2}$ (ESI Fig. S6 $\left.{ }^{\dagger}\right) .{ }^{16}$ The large energy separation between the emission wavelength maximum (compound 1 at $620 \mathrm{~nm}$, compound 2 at $520 \mathrm{~nm}$ ) and the nearest excitation wavelength maximum (compound $\mathbf{1}$ at $520 \mathrm{~nm}$, compound 2 at $450 \mathrm{~nm}$ ) is probably due to the forbidden transition from the ground state to the first excited triplet level. The R.T. PL quantum efficiencies of compounds 1 and 2 are $29 \%$ and $39 \%$ respectively, and characteristic PL lifetimes are $4.83 \mathrm{~ms}$ and $3.31 \mathrm{~ms}$ respectively (ESI Fig. S7 and $\mathrm{S} 8 \dagger$ ). The longer lifetime of $\mathrm{Mn}_{2}$ dimers might be related to the fact that the ligand field was rigidified by these hydrogenbonding interactions (Fig. S1 $\dagger$ ), which efficiently decreased some nonradiative loss decay induced by vibrational relaxation. The emission peaks and the emission decay time of compounds $\mathbf{1}$ and $\mathbf{2}$ hardly changed at different excitation wavelengths (ESI Fig. S9, S10 and Table S5 $\dagger$ ). They further showed that the emission of compounds $\mathbf{1}$ and $\mathbf{2}$ is $\mathrm{d}-\mathrm{d}$ transition (from the lowest excited triplet state ${ }^{4} T_{1}$ to the ground state ${ }^{6} \mathrm{~A}_{1}$ ) phosphorescent emission of the manganese(II) ion in the $\mathrm{d}^{5}$ configuration.

Interestingly, compound 1 changed the PL colour from red to green upon continuous one-minute thermal treatment at $90{ }^{\circ} \mathrm{C}$ (Fig. 2a-c). The thermochromic luminescence process was recorded by fluorescence microscopy (Fig. 2a). The corresponding emission spectra exhibited the gradual disappearance of the $620 \mathrm{~nm}$ peak, and the simultaneous appearance of the $520 \mathrm{~nm}$ peak (Fig. 2b). In the Commission Internationale de l'Eclairage (CIE) coordinates (Fig. 2c), the
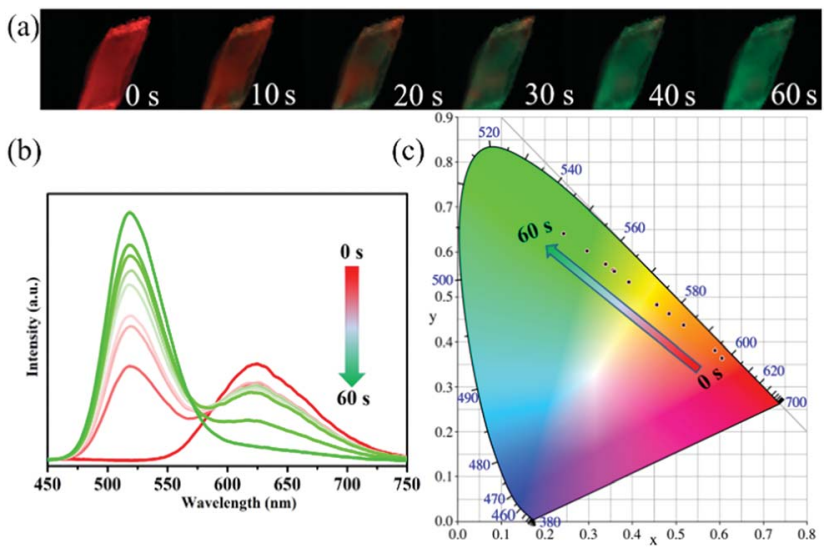

Fig. 2 Thermochromic luminescence of compound 1 under thermal treatment at $90{ }^{\circ} \mathrm{C}$. ( $\mathrm{a}$ and b) Time-dependent PL photos and the emission spectra $\left(\lambda_{\mathrm{Ex}}=360 \mathrm{~nm}\right)$ of crystal 1 at $90^{\circ} \mathrm{C}$. (c) Commission Internationale de l'Eclairage (CIE) chromaticity coordinates corresponding to the emission.

luminescence colour of $\mathbf{1}$ gradually changed from red (0.61, $0.36)$ to green $(0.24,0.64)$ with thermal treatment time. As the luminescence colour of compound $\mathbf{1}$ after thermal treatment at $90{ }^{\circ} \mathrm{C}$ is consistent with that of compound 2 at R.T. (ESI Fig. S11†), we hypothesized that there was a thermally induced structural transformation from 1 to 2 through a reaction shown in Fig. 3a, in which compound 1 could be decomposed into compound $2, \mathrm{C}_{4} \mathrm{NOH}_{10} \mathrm{Cl}$ and ethanol. That is to say, the structure of $\left[\mathrm{Mn}_{2} \mathrm{Cl}_{9}\right]^{5-}$ dimers in compound 1 might decompose into two units $\left[\mathrm{MnCl}_{4}\right]^{2-}$ with the departure of ethanol molecules, producing compound 2 (Fig. 3b).

To examine the thermally induced structural transformation from compound 1 to 2, PXRD was used to characterize the structural and phase changes at $90{ }^{\circ} \mathrm{C}$. It is a pity that we could not obtain a high quality single-crystal of $\mathbf{1}$ after thermal treatment at $90{ }^{\circ} \mathrm{C}$ for SCXRD. Nevertheless, we could find

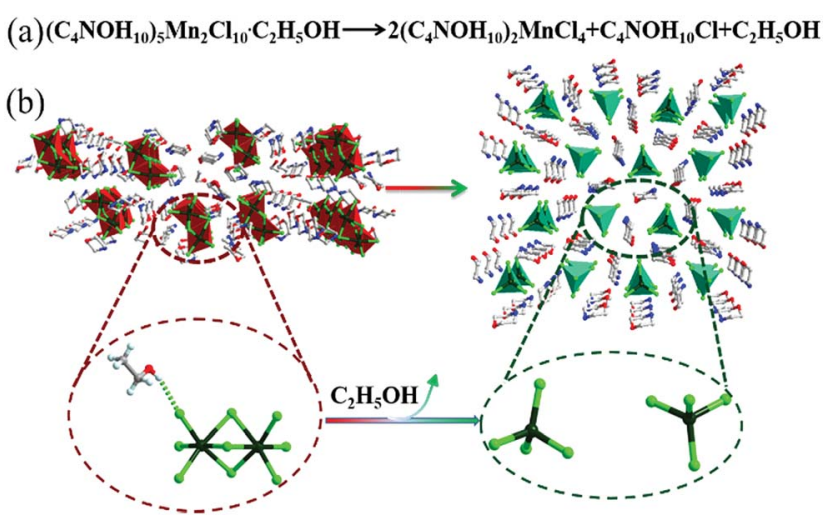

Fig. 3 Proposed solvent induced structure conversion reaction. (a) Predicting the balanced reaction of the transition process from compound 1 to 2 . (b) Predicting the transition process from compound 1 to 2 . 
evidence in the PXRD pattern of the thermally treated compound $\mathbf{1}$, in which diffraction peaks of compound 2 and the $\mathrm{C}_{4} \mathrm{NOH}_{10} \mathrm{Cl}$ phase appeared and those of compound 1 disappeared, indicating that the compound $\mathbf{1}$ crystal is transformed into compound 2 (Fig. 4a). In order to further study the structural transformation, thermogravimetric analysis (TGA) and differential scanning calorimetry (DSC) of compound 1 were performed (Fig. 4b). The TGA plot of compound $\mathbf{1}$ has a small stable plateau at about $90{ }^{\circ} \mathrm{C}$ and the material starts to decompose at $150{ }^{\circ} \mathrm{C}$. The decomposition temperature starting point of compound $\mathbf{1}$ is similar to that of compound $\mathbf{2}$ and $\mathrm{C}_{4} \mathrm{NOH}_{10} \mathrm{Cl}$ (ESI Fig. S12 $\dagger$ ). It is due to the presence of intermolecular hydrogen bonds that compound 1 lost ethanol molecules at $90^{\circ} \mathrm{C}$. In the DSC plot, the change of $\left[\mathrm{Mn}_{2} \mathrm{Cl}_{9}\right]^{5-}$ is induced by the departure of the ethanol molecule at $90{ }^{\circ} \mathrm{C}$. The PL changes from the red emission of six coordinate $\left[\mathrm{Mn}_{2} \mathrm{Cl}_{9}\right]^{5-}$ to green emission of four coordinate $\left[\mathrm{MnCl}_{4}\right]^{2-}$ with losing equivalent ethanol, and the whole process is irreversible. As proposed above, a solid state balanced reaction of the transition process from compound 1 to 2 was proposed: $\left(\mathrm{C}_{4} \mathrm{NOH}_{10}\right)_{5}$ $\mathrm{Mn}_{2} \mathrm{Cl}_{9} \cdot \mathrm{C}_{2} \mathrm{H}_{5} \mathrm{OH} \rightarrow 2\left(\mathrm{C}_{4} \mathrm{NOH}_{10}\right)_{2} \mathrm{MnCl}_{4}+\mathrm{C}_{4} \mathrm{NOH}_{10} \mathrm{Cl}+\mathrm{C}_{2} \mathrm{H}_{5} \mathrm{OH}$.
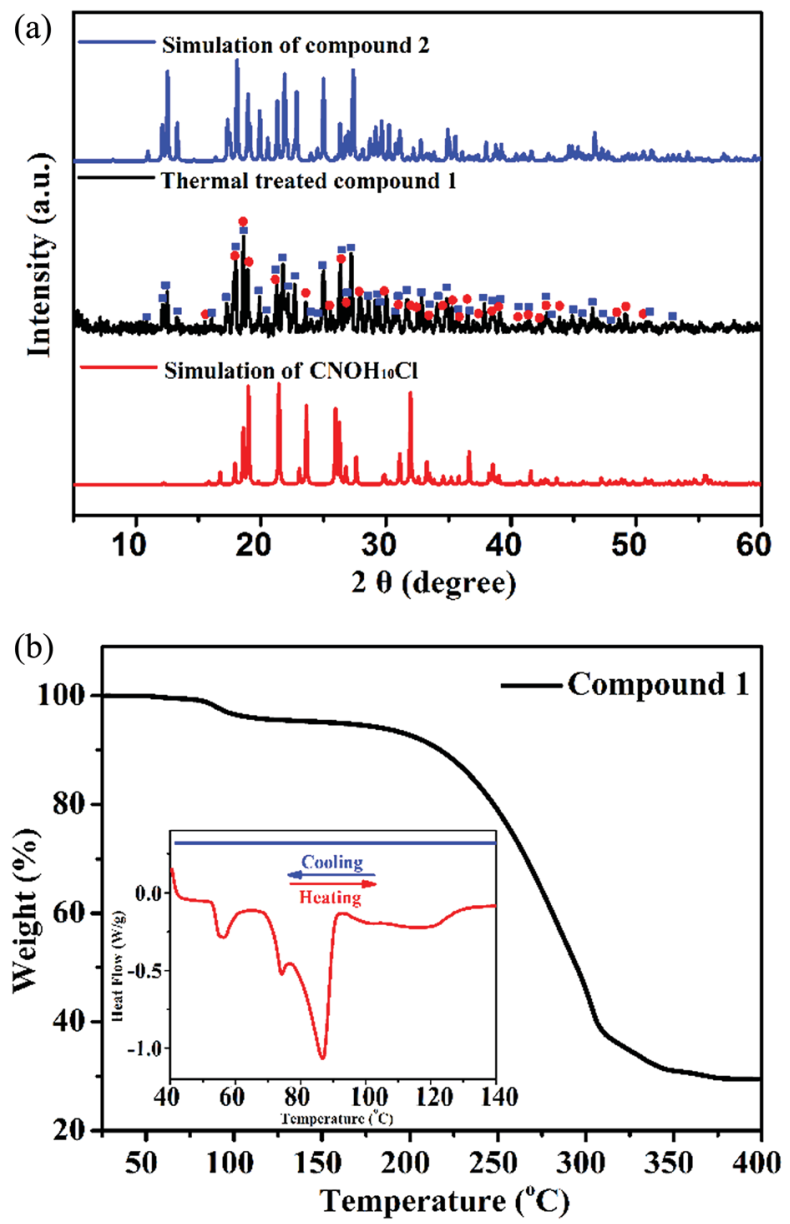

Fig. 4 (a) PXRD of the thermally treated 1 crystal (blue squares: patterns from the compound 2 phase; red circles: patterns from the $\mathrm{C}_{4} \mathrm{NOH}_{10} \mathrm{Cl}$ phase). (b) TGA plot of compound 1 (inset: DSC plot for 1).

\section{Conclusions}

In summary, we have reported the synthesis and structure of a binuclear organic manganese chloride cluster in octahedral coordination, which demonstrated thermally induced structural transformation into a monomanganese halide in tetrahedral coordination and the synchronous thermochromic luminescence response. The structural transformation involves the cleavage of metal halide bonds followed by structural reorganization, which was characterized by crystallographic analysis, spectroscopic methods and TGA. Our research extends the ability to assemble hybrids of organic-inorganic metal halides with controlled structures in a rational manner and contributes to a better understanding of the thermal stability of metal halides. And the ecofriendly, hypotoxicity, high performance light emitting crystals and rapid conversion of luminescence from red to green represented a major breakthrough in the field of light emitting materials.

\section{Conflicts of interest}

There are no conflicts to declare.

\section{Acknowledgements}

We acknowledge the support from the National Science Fund for Distinguished Young Scholars (21825106), the National Natural Science Foundation of China (21671175), the Program for Science \& Technology Innovation Talents in Universities of Henan Province (164100510005), the Program for Innovative Research Team (in Science and Technology) in Universities of Henan Province (19IRTSTHN022) and Zhengzhou University.

\section{Notes and references}

1 (a) L. J. Xu, C. Z. Sun, H. Xiao, Y. Wu and Z. N. Chen, $A d v$. Mater., 2017, 29, 981-985; (b) H. Y. Ye, Q. Zhou, X. Niu, W. Q. Liao, D. W. Fu, Y. Zhang, Y. M. You, J. Wang, Z. N. Chen and R. G. Xiong, J. Am. Chem. Soc., 2015, 137, 13148-13154.

2 P. S. Kuttipillai, Y. Zhao, C. J. Traverse, R. J. Staples, B. G. Levine and R. R. Lunt, Adv. Mater., 2016, 28, 320-326.

3 Y. Zhao and R. R. Lunt, Adv. Energy Mater., 2013, 3, 11431148.

4 C. Zhou, H. Lin, M. Worku, J. Neu, Y. Zhou, Y. Tian, S. Lee, P. Djurovich, T. Siegrist and B. Ma, J. Am. Chem. Soc., 2018, 140, 13181-13184.

5 C. Zhou, H. Lin, H. Shi, Y. Tian, C. Pak, M. Shatruk, Y. Zhou, P. Djurovich, M. Du and B. Ma, Angew. Chem., Int. Ed., 2018, 57, 1021-1024.

6 K. R. Kyle, K. R. Chong, P. C. Ford and J. A. Dibenedetto, J. Am. Chem. Soc., 1991, 113, 2954-2965.

7 C. Zhou, H. Lin, S. Lee, M. Chaaban and B. Ma, Mater. Res. Lett., 2018, 6, 552-569.

8 (a) A. S. Berezin, D. G. Samsonenko, V. K. Brel and A. V. Artem'ev, Dalton Trans., 2018, 47, 7306-7315; (b) G. E. Hardy and J. I. Zink, Inorg. Chem., 1976, 15, 3061- 
3065; (c) Y. Wu, X. Zhang, Y. Q. Zhang, M. Yang and Z. N. Chen, Chem. Commun., 2018, 54, 13961-13964; (d) A. S. Berezin, K. A. Vinogradova, V. A. Nadolinny, T. S. Sukhikh, V. P. Krivopalov, E. B. Nikolaenkova and M. B. Bushuev, Dalton Trans., 2018, 47, 1657-1665; (e) X. Zhu, W. Y. Zhang, C. Chen, Q. Ye and D. W. Fu, Dalton Trans., 2018, 47, 2344-2351; (f) S. Balsamy, P. Natarajan, R. Vedalakshmi and S. Muralidharan, Inorg. Chem., 2014, 53, 6054-6059; $(g)$ Y. Zhang, W. Q. Liao, D. W. Fu, H. Y. Ye, C. M. Liu, Z. N. Chen and R. G. Xiong, Adv. Mater., 2015, 27, 3942-3946.

9 T. Naito, T. Inabe, K. Takeda, K. Awaga, T. Akutagawa, T. Hasegawa, T. Nakamura, T. Kakiuchi, H. Sawa, T. Yamamoto and H. Tajima, J. Mater. Chem., 2001, 11, 2221-2227.

10 J. D. Martin, R. F. Hess and P. D. Boyle, Inorg. Chem., 2004, 43, 3242-3247.

11 (a) S. Flan-drois, N. B. Chanh, R. Duplessix, T. Maris and P. Negrier, Phys. Status Solidi A, 1995, 149, 697-710; (b) H. Arend and H. Gränicher, Ferroelectrics, 1976, 13, 537-
539; (c) Z. Nie, J. Yin, H. Zhou, N. Chai, B. Chen, Y. Zhang, K. Qu, G. Shen, H. Ma, Y. Li, J. Zhao and X. Zhang, ACS Appl. Mater. Interfaces, 2016, 8, 28187-28193.

12 Z. X. Wang, P. F. Li, W. Q. Liao, Y. Tang, H. Y. Ye and Y. Zhang, Chem.-Asian J., 2016, 11, 981-985.

13 (a) R.-B. Lin, S.-Y. Liu, J.-W. Ye, X.-Y. Li and J.-P. Zhang, Adv. Sci., 2016, 3, 1500434; (b) B. Li, H.-T. Fan, S.-Q. Zang, H.-Y. Li and L.-Y. Wang, Coord. Chem. Rev., 2018, 377, 307-329.

14 (a) I. O. Koshevoy, Y.-C. Chang, A. J. Karttunen, M. Haukka, T. Pakkanen and P.-T. Chou, J. Am. Chem. Soc., 2012, 134, 6564-6567; (b) Q. Benito, X. F. Le Goff, S. Maron, A. Fargues, A. Garcia, C. Martineau, F. Taulelle, S. Kahlal, T. Gacoin, J. P. Boilot and S. Perruchas, J. Am. Chem. Soc., 2014, 136, 11311-11320.

15 M. Wu, Q. Zhou, L. Dolgov, R. I. Srivastava, L. Zhou, Z. Wang, J. Shi, M. D. Dramićanin and M. Brik, J. Mater. Chem. C, 2018, 6, 2652-2671.

16 Y. Zhang, W. Q. Liao, D. W. Fu, H. Y. Ye, Z. N. Chen and R. G. Xiong, J. Am. Chem. Soc., 2015, 137, 4928-4931. 